\title{
Influence of different fillers on the properties of an experimental vinyl polysiloxane
}

\section{Débora Könzgen MEINCKE Aline de Oliveira OGLIARI(a) Fabrício Aulo OGLIAR I(b)}

(a) Universidade Federal de Pelotas - UFPel, School of Dentistry, Biomaterials Development and Control Center, Pelotas, RS, Brazil.

(b) Universidade Federal de Pelotas - UFPel, School of Materials Engineering, Pelotas, RS, Brazil.
Declaration of Interests: The authors certify that they have no commercial or associative interest that represents a conflict of interest in connection with the manuscript.

\section{Corresponding Author:}

Fabrício Aulo Ogliari

e-mail: ogliari@gmail.com

DOI: 10.1590/1807-3107BOR-2016.vol30.0036

Submitted: Aug 09, 2015

Accepted for publication: Sep 22, 2015

Last revision: Nov 18, 2015
Abstract: The aim of the study was to evaluate the effect of the incorporation of different fillers on an experimental vinyl polysiloxane (VPS) at two different concentrations, $20 \%$ and $40 \%$. Different fillers were added to an experimental VPS. The study was developed in two stages: (i) incorporation of fillers in different concentrations: (a) $20 \mathrm{wt} \%$ fillers, and (b) $40 \mathrm{wt} \%$. The fillers were added to experimental VPS and mixed with a speed mixer; (ii) characterization of experimental VPS; after the base paste and catalyst paste were mixed, the experimental VPS was used to make specimens specifically for each test, which were stored at $23^{\circ} \mathrm{C}$ for 24 hours. The tests were designed according to the specific standardization for the analysis of tensile strength, detail reproduction, Shore A hardness, and elastic recovery. For analysis of filler size pattern, scanning electron microscopy at 1500× magnification was used. The aerosil OX-50 40\% (AE), and pure aluminum hydroxide $40 \%$ (PAH) groups presented the highest tensile strength and Shore A hardness values. However, those were the only groups that did not present continuous detail reproduction of an intersection of $20 \mu \mathrm{m}$ line. The elastic recovery was not statistically significant. The undesirable characteristics of VPS (lowest Shore A hardness and tensile strength) were observed when it was added to the composition of acrylic polymer (AP) and fiberglass (FG) in both concentrations, $20 \%$ and $40 \%$. In groups $\mathrm{AE}$ and $\mathrm{PAH}$, agglomerates of nanofillers were shown in SEM micrography, while the other groups presented different shapes and fillers sizes.

Keywords: Dental Impression Materials; Microscopy; Elementary Particles; Silicone Elastomers; Tensile Strength.

\section{Introduction}

Addition silicones or vinyl polysiloxanes are elastomeric impression materials that have several advantages: resistance to rupture, moderate working times, fast elastic recovery, no smell or taste and usability even one week after preparation of the stone plaster cast model in dentistry. ${ }^{1}$ The material is divided into two pastes, base and catalyst. Crosslinking occurs when the vinyl groups react with the hydride groups, which are catalyzed by platinum without generating by-products. ${ }^{2}$ The material has different viscosities and can be used in different techniques. The light composition is fluid enough to flow and copy gingival crevices, while the 
putty version is viscous enough to promote removal of soft tissue and retain the impression.

Generally, vinyl polysiloxanes are used when a good copy is necessary for the production of dental prostheses and indirect restorations without distortions. ${ }^{3}$ Despite technical improvements, such as CAD/CAM and 3-D systems, the conventional impression process continues to play an important role in the transfer of patient information to the dental laboratory. ${ }^{4}$ The impression is the main step in obtaining a well-adjusted restoration, therefore, the ability reproduce details, elastic recovery, and resistance to tensile strength are of primary importance for producing dental prostheses without the need for adjustments.

Fillers are used in dentistry in various materials such as composite resin, resin cements, glass ionomer and many others. There are different reasons for choosing fillers for dental materials, related to providing them with color, translucence, ${ }^{5}$ opalescence, ${ }^{6}$ radiopacity, ${ }^{7,8}$ rheology $y^{9}$ and appropriate resistance. In the formulation of vinyl polysiloxanes, many variations can usually be combined. The inherent characteristics of the filler determine the majority of the material properties. When size, surface area, and different shapes are properly combined, it improves the properties of vinyl polysiloxanes. ${ }^{10}$

The addition of inorganic and organic fillers is very common to reinforce the mechanical strength of polymers ${ }^{11}$ and to increase their mechanical properties, because the rigidity of inorganic agents is more relevant with regard to the organic portion of the polymer. ${ }^{12}$ In most applications, sílica has been used as the main type of reinforcing filler used to increase the properties ${ }^{13}$ of vinyl polysiloxanes, however, other types of non-black fillers are also used such as calcium carbonate, diatomite and fiberglass.

A filler must make intimate contact with the elastomer chains if it is going to contribute to the reinforcement of the rubber-filler composite. Fillers with a large surface area have more contact area available, and therefore, have a higher potential for reinforcement. This makes it very important to have a shape with the desired properties ${ }^{14}$ to influence the viscosity, and consequently, the material properties. ${ }^{15,16}$
The aim of this study was to evaluate different properties of a vinyl polysiloxanes using ten different fillers in two different concentrations, $20 \%$ and $40 \%$, added to a polymer matrix of an experimental vinyl polysiloxanes. The null hypothesis was that there would be no significant difference in the properties with regard to these types of fillers and their concentration in the material.

\section{Methodology}

The experimental vinyl polysiloxane without fillers (VPS) was produced by the company Yller and used to determine all the characterizations. The basic composition is described in Table 1 .

Ten different types of fillers in two different concentrations, $20 \mathrm{wt} \%$ and $40 \mathrm{wt} \%$, were incorporated into the experimental VPS for further evaluation. The fillers and the manufactures are described in Table 2.

The fillers were added to a composition of $30 \mathrm{~mL}$ of base paste and $30 \mathrm{~mL}$ of catalyst paste. The materials were inserted in individual vials and mixed in a rapid mixing machine (SpeedMixer DAC150.1FVZ; Synergy Devices; High Wycombe, United Kingdom) at 3500 rpm for 60 seconds. For all the groups and all the tests, the two pastes of VPS were mixed with self-mixing tips.

Tensile strength analysis was performed using a rectangular mold ( $50 \mathrm{~mm} \times 16 \mathrm{~mm} \times 1.5 \mathrm{~mm}$ ) with a central constriction $(8 \mathrm{~mm})$, as an hourglass. The mold was filled with experimental VPS, and a polyester strip and a glass slide were placed onto the filled molds. After five minutes, the specimens $(\mathrm{n}=10)$ were removed and stored at room temperature $\left(23^{\circ} \mathrm{C}\right)$ for 24 hours. The universal testing machine (DL500; EMIC; São José dos Pinhais, Brazil) with two claws moving in opposite directions at a speed of $0.5 \mathrm{~mm} / \mathrm{min}$, was used to pull the specimen to the point of failure.

A detail reproduction test was performed in accordance with the ISO 4823:2000 standard, by using a mold with three horizontal lines measuring $20 \mu \mathrm{m}, 50 \mu \mathrm{m}$ and $75 \mu \mathrm{m}$ and two vertical lines

Table 1. Experimental vinyl polysiloxane composition (VPS).

\begin{tabular}{lc}
\hline Base & Catalyst \\
\hline Vinyl Polysiloxane & Vinyl Polysiloxane \\
Polymethyl hydrogen siloxane & Platinum complex
\end{tabular}


Table 2. Fillers used in the experimental VPS of $20 \mathrm{wt} \%$ and $40 \mathrm{wt} \%$

\begin{tabular}{|c|c|}
\hline Fillers used & Manufacturer \\
\hline Acrylic polymer (AP) & TDV Dental Ltda., Blumenau, Brazil \\
\hline Aerosil OX-50 (AE) & \#325, Evonik Industries, Stadtbezirke III, Essen, Germany \\
\hline Aluminum hydroxide (AHM) & \#325, Minerali, Mogi Guaçu, Brazil \\
\hline Calcined alumina (CA) & Minerali, Mogi Guaçu, Brazil \\
\hline Cristobalite (CB) & Asfer Indústria Química Ltda., São Caetano do Sul, Brazil \\
\hline Diatomaceous earth (DE) & \#325 CX, Ciemil, Campinas, Brazil \\
\hline Fiberglass (FG) & Roving Picotada, Casa da Resina/Owens Corning, Belo Horizonte, Brazil \\
\hline Halloysite (HAL) & Sigma-Aldrich, St. Louis, USA \\
\hline Pure aluminum hydroxide (PAH) & Vetec Química Fina, Rio de Janeiro, Brazil \\
\hline Quartz (QT) & \# 1000, Brasil Minas, São Paulo, Brazil \\
\hline
\end{tabular}

that cut their ends. The lines were molded, and the intersection of the horizontal and vertical lines created after taking the impression, was evaluated. After five minutes, the specimens $(n=3)$ were removed and stored at room temperature $\left(23^{\circ} \mathrm{C}\right)$ for 24 hours. The samples were observed using a stereomicroscope (100×). The detail reproduction of an intersection of $20 \mu \mathrm{m}$, reproduced continuously, was considered satisfactory.

The Shore A hardness test was performed in accordance with the ISO 868 standard, by using the matrix (thickness $0.6 \mathrm{~cm} \times$ diameter $1.5 \mathrm{~cm}$ ) to make specimens for test. The mould was filled with experimental VPS, and a polyester strip and a glass slide were placed onto the filled molds. After five minutes, the specimens $(n=3)$ were removed and stored at room temperature $\left(23^{\circ} \mathrm{C}\right)$ for 24 hours. A digital durometer (Shore A Durometer; Mitutoyo; Kawasaki, Japan) was used to determine the hardness in three different points, and the mean values were calculated.

The elastic recovery test was performed in accordance with the ISO 4823:2000 standard, by using a cylindrical mold (thickness $1.25 \mathrm{~cm} x$ diameter $2.0 \mathrm{~cm}$ ) filled with experimental VPS. After 5 minutes, the specimens $(n=3)$ were removed and stored at room temperature $\left(23^{\circ} \mathrm{C}\right)$ for 24 hours and evaluated according to the following the equation:

$$
K=100-\left[100\left(\frac{h_{1}-h_{2}}{h_{0}}\right)\right] \text {, }
$$

where $k$ is the constant of elastic recovery, $h_{0}$ the height of the model, $h_{1}$ the initial reading of the indicator and $h_{2}$ the final reading of the indicator (immediately after the deforming force has been removed from the sample).

The morphology of inorganic fillers was examined by scanning electron microscopy (SEM) (JSM-6610/LV; JEOL; Waltham, USA). The fillers were covered with gold and analyzed at 1500× magnification.

Data were analyzed using ANOVA One Ranks, Dunn test with $p<0.001$ for tensile strength tests, and one-way ANOVA and Tukey test with $p<0.05$ for Shore A hardness and elastic recovery tests.

\section{Results}

Figure 1 and the Figure 2 show the results of the mechanical tensile strength test. The groups with concentrations of $20 \mathrm{wt} \%$ fillers presented half the force values $(\mathrm{N})$ compared with those with the concentration of $40 \mathrm{wt} \%$ fillers. However, for acrylic polymer (AP), aluminum hydroxide (AHM), fiberglass (FG) and quartz (QT) fillers, despite the increase in filler concentration, no significant increase in mechanical tensile strength was observed. The aerosil OX-5O (AE) and pure aluminum hydroxide (PAH) fillers showed increased resistance with increase in filler loading. The lowest results shown were for acrylic polymer (AP) aluminum hydroxide (AHM), fiberglass (FG) and quartz (QT) fillers for both concentrations.

Detail reproduction tests of groups aerosil OX-5O (AE) and pure aluminum hydroxide (PAH) fillers in both concentration showed they did not create a satisfactory reproduction, while for the other groups, a continuous detail reproduction of the $20 \mu \mathrm{m}$ line was shown (Figure 3). 


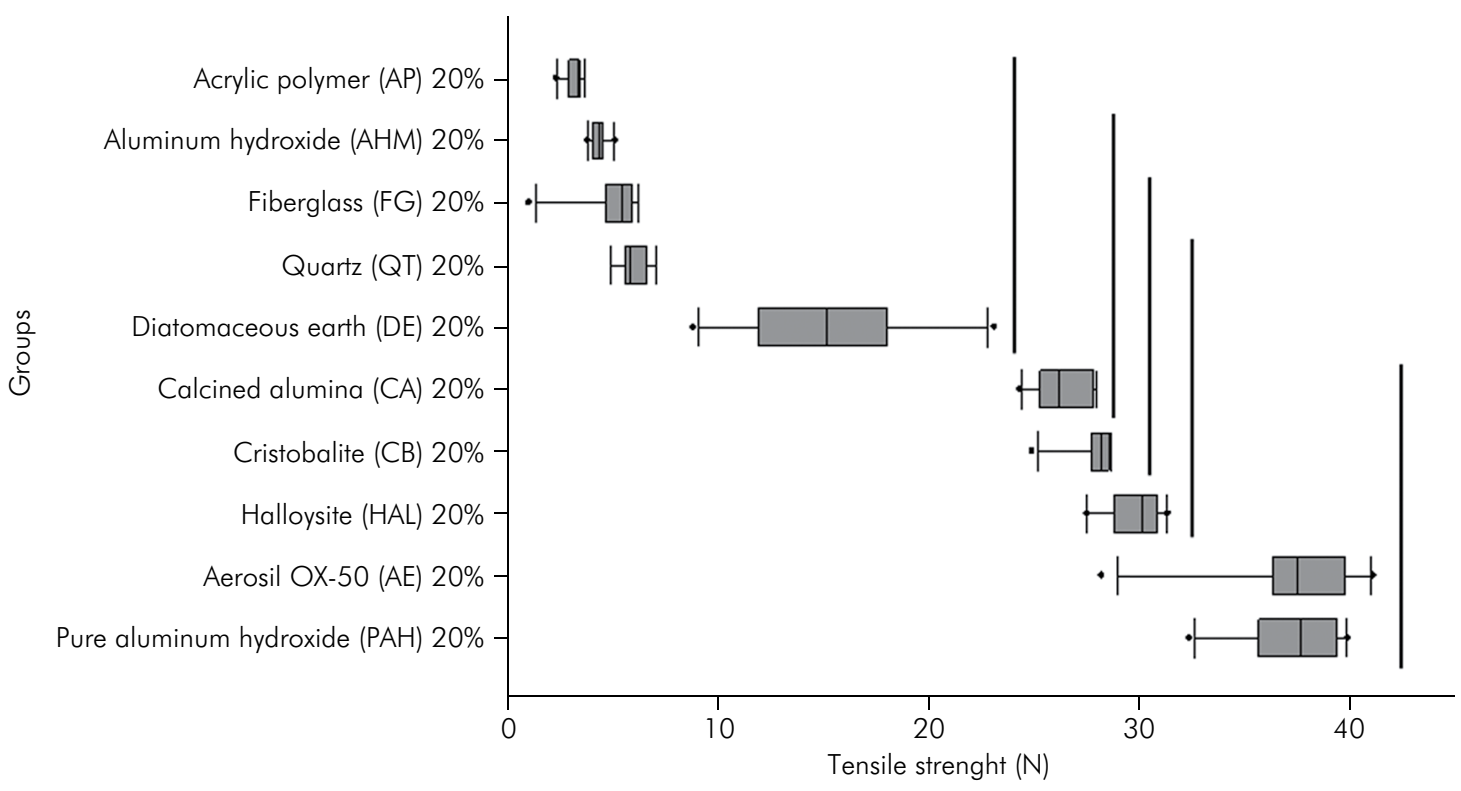

Figure 1. Mechanical tensile strength found in groups with concentrations of $20 \mathrm{wt} \%$ fillers ( $\mathrm{n}=10$ ) (ANOVA One Ranks, Dunn Test $p<0.001)$.

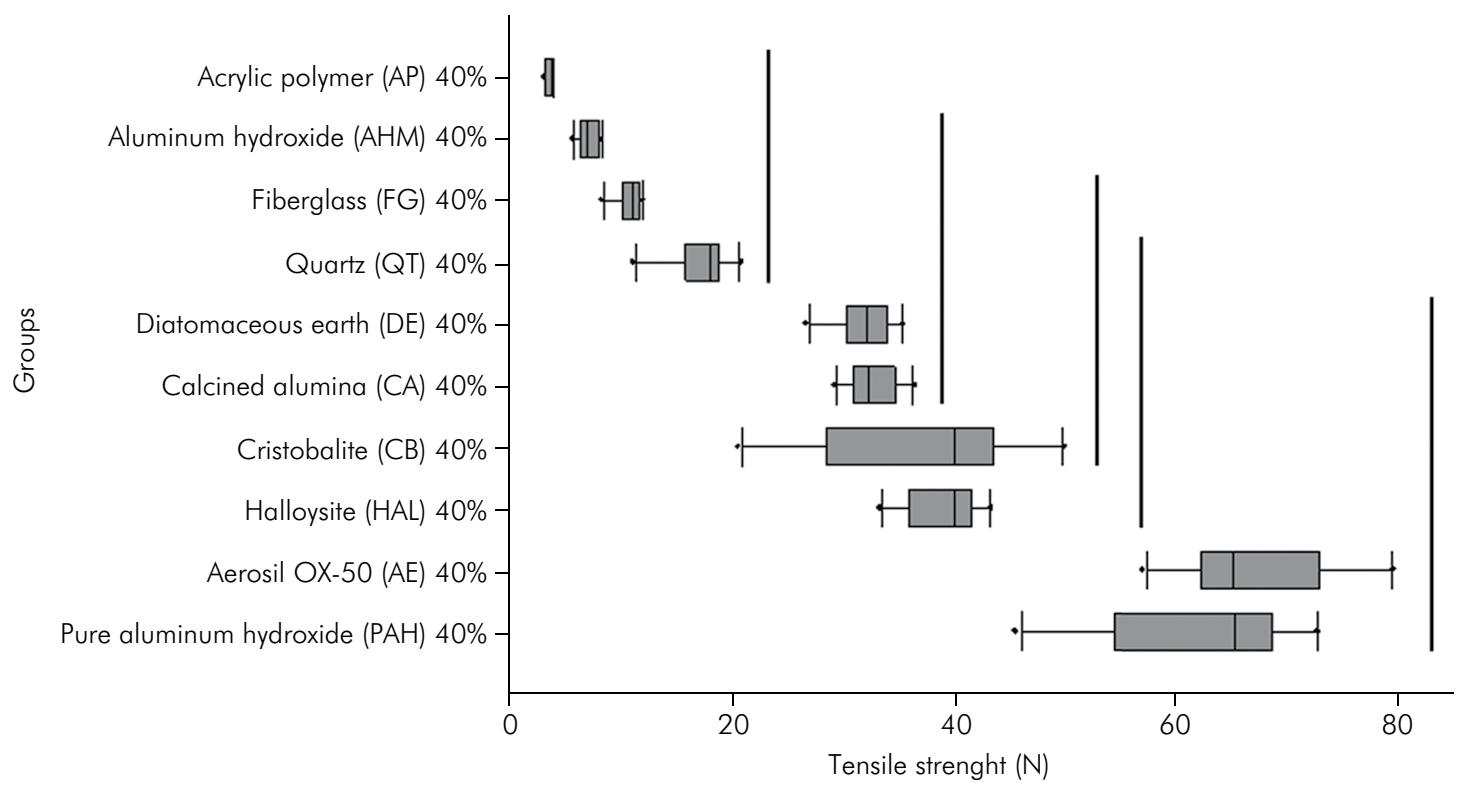

Figure 2. Mechanical tensile strength found in groups with concentrations of $40 \mathrm{wt} \%$ fillers ( $\mathrm{n}=10$ ) (ANOVA One Ranks, Dunn Test $\mathrm{p}<0.001)$.

After analysis, it was concluded there was no statistically significant difference between the groups for elastic recovery, whereas Shore A hardness presented different results for the different fillers. The highest hardness values were shown in the aerosil OX-50 (AE 40\%) and pure aluminum hydroxide
(PAH 40\%) groups, and the lowest for the cristobalite (CB 20\%) and fiberglass (FG 20\%) groups, which were statistically similar (Table 3).

The morphological characteristics of different types of fillers are shown in Figure 4. Some were shown to be stick-shaped, such as those of fiberglass (FG), 

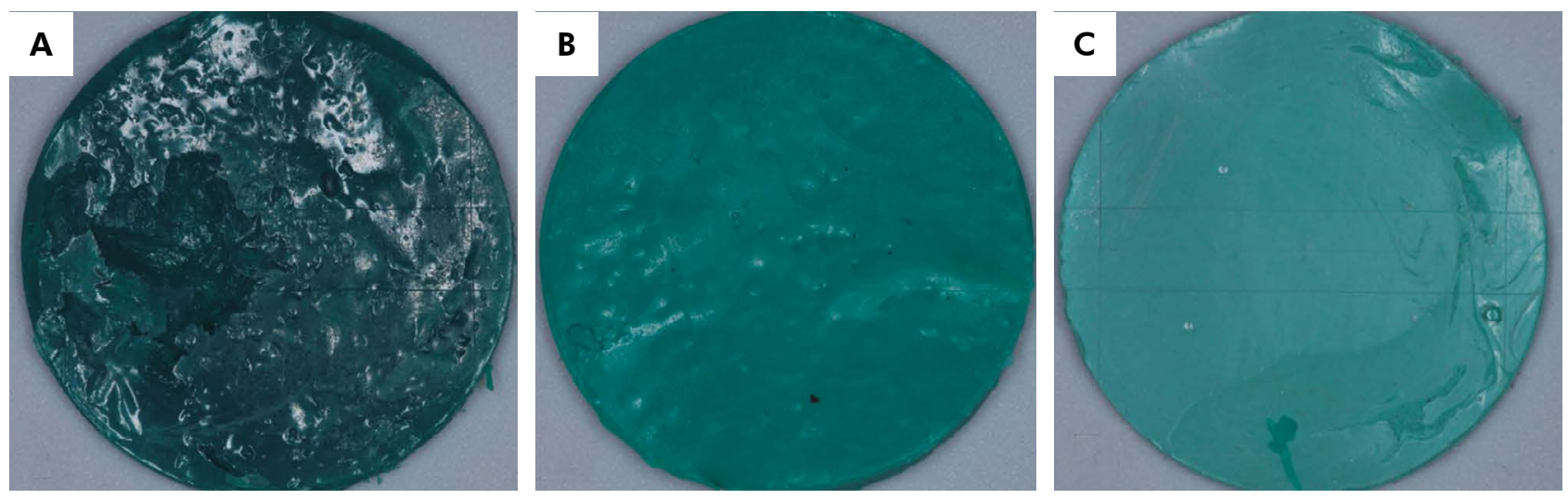

Figure 3. Detail reproduction of lines measuring $20 \mu \mathrm{m}, 50 \mu \mathrm{m}$ and $75 \mu \mathrm{m}$. (A) aerosil OX-50 (AE) 40 wt\%, (B) pure aluminum hydroxide (PAH) $40 \mathrm{wt} \%$, (C) calcined alumina (CA) $40 \mathrm{wt} \%$.

others were spherical-shaped such as those of acrylic polymer (AP). Nevertheless, some had the appearance of single fillers, and in reality they were agglomerates of nanofillers, such as those of aerosil OX-50 (AE) and

Table 3. Means (standard deviations) of Shore A hardness $(n=3)$ and elastic recovery $(n=3)$.

\begin{tabular}{|c|c|c|}
\hline & Shore A Hardness & Elastic Recovery* \\
\hline AP $20 \%$ & $24.7( \pm 1.79)^{\llcorner}$ & $99.07( \pm 0.72)$ \\
\hline AP $40 \%$ & $23.4( \pm 4.39)^{\operatorname{LM}}$ & $99.69( \pm 0.36)$ \\
\hline AE $20 \%$ & $48.4( \pm 1.56)^{\mathrm{C}}$ & $99.76( \pm 0.19)$ \\
\hline AE $40 \%$ & $67.3( \pm 4.40)^{\mathrm{A}}$ & $99.84( \pm 0.32)$ \\
\hline AHM 20\% & $31.0( \pm 2.03)^{\mathrm{JK}}$ & $99.52( \pm 0.29)$ \\
\hline AHM 40\% & $38.6( \pm 1.14)^{\mathrm{DEFGHI}}$ & $99.67( \pm 0.43)$ \\
\hline CA $20 \%$ & $32.7( \pm 3.67)^{\mathrm{IJK}}$ & $99.51( \pm 0.36)$ \\
\hline CA $40 \%$ & $43.6( \pm 1.95)^{\mathrm{CDEF}}$ & $99.66( \pm 0.31)$ \\
\hline CB $20 \%$ & $17.2( \pm 3.40)^{\mathrm{MN}}$ & $99.29( \pm 0.78)$ \\
\hline CB $40 \%$ & $44.9( \pm 1.98)^{\mathrm{CD}}$ & $99.77( \pm 0.31)$ \\
\hline DE $20 \%$ & $44.9( \pm 1.64)^{C D E}$ & $99.40( \pm 0.78)$ \\
\hline DE $40 \%$ & $59.5( \pm 5.18)^{\mathrm{B}}$ & $99.76( \pm 0.25)$ \\
\hline FG 20\% & $14.5( \pm 2.69)^{\mathrm{N}}$ & $99.42( \pm 0.67)$ \\
\hline FG $40 \%$ & $23.8( \pm 1.67)^{\llcorner}$ & $99.83( \pm 0.21)$ \\
\hline HAL 20\% & $37.3( \pm 2.75)^{\mathrm{FGHI}}$ & $99.72( \pm 0.26)$ \\
\hline HAL $40 \%$ & $47.9( \pm 4.59)^{c}$ & $99.61( \pm 0.53)$ \\
\hline PAH $20 \%$ & $48.8( \pm 1.68)^{\mathrm{C}}$ & $99.32( \pm 0.47)$ \\
\hline PAH $40 \%$ & $68.7( \pm 2.71)^{\mathrm{A}}$ & $98.91( \pm 0.39)$ \\
\hline QT 20\% & $31.5( \pm 1.00)^{\mathrm{Jk}}$ & $99.91( \pm 0.13)$ \\
\hline QT 40\% & $45.6( \pm 1.48)^{\mathrm{C}}$ & $99.77( \pm 0.22)$ \\
\hline
\end{tabular}

Data were analyzed separately using one-way ANOVA and Tukey tests. Different letters in the same column indicate statistically significant differences $(p<0.05)$.

*The groups presented no statistically significant difference $(p>0.05)$. pure aluminum hydroxide (PAH); irregular shapes were also shown in the SEM micrograph, with more superficial areas, such as those of the diatomaceous earth (DE), halloysite (HAL), calcined alumina (CA) fillers, the cited Figure 4 are F, H, A, E, J, G and B, respectively.

\section{Discussion}

Filler is the most-used term for referring to material that is intended to augment weight or fill space. Although the original purpose of fillers in commodity materials was to lower the cost of products, nowadays it is very important to select the filler characteristics desirable for promoting better mechanical or optical properties in the material. Unreinforced polymers often exhibit properties that do not meet the technical specifications demanded. The addition of mineral/inorganic fillers, adequately surface-treated, contribute to changes with respect to mechanical properties such as hardness and tensile strength.

The fillers shown in Figure 2. have different morphological characteristics. Most fillers are isometric; others are spherical; others are fiber-shaped or aggregate into clusters. ${ }^{17}$ In Figure 4A (aerosil OX-50) it is possible to observe clustered fillers. Silica has small primary fillers that are joined together with other fillers of a similar size to make up larger aggregate structures. This cluster structure is not permanent, because hydrogen bonding among fillers will form clusters or aggregates constantly. ${ }^{14}$ The 

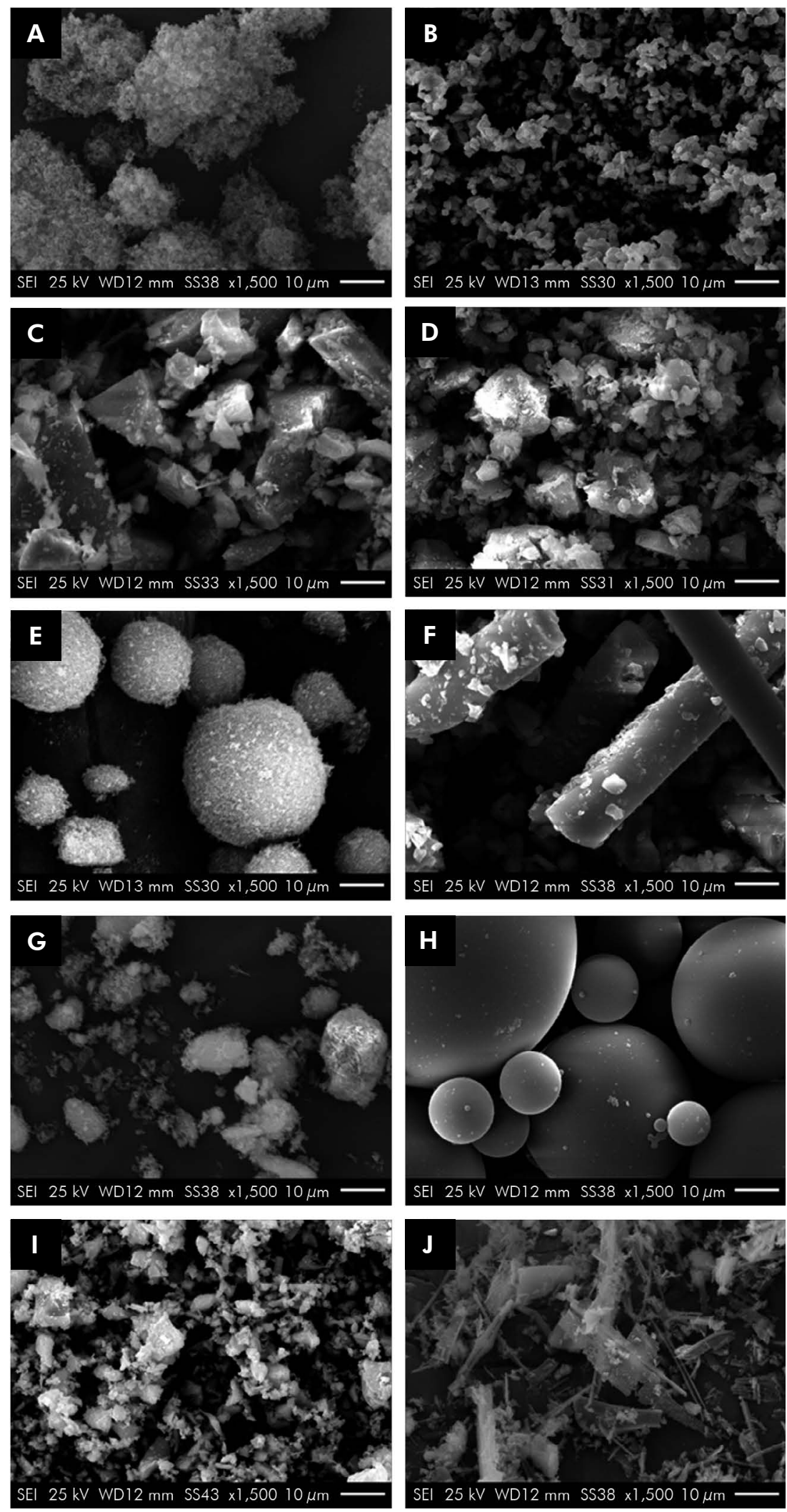

Figure 4. SEM micrographs showing the morphology of the different fillers: (A) aerosil OX-50; (B) calcined alumina; (C) cristobalite; (D) aluminum hydroxide; (E) pure aluminum hydroxide; (F) fiberglass; $(G)$ halloysite; $(H)$ acrylic polymer; (I) quartz and (J) diatomaceous earth. 
small size of this filler favors the increased viscosity of the elastomer, reducing the flow and copy capacity.

Pure aluminum hydroxide and aluminum hydroxide $\mathrm{Al}(\mathrm{OH})_{3}$ fillers, shown in Figure $4 \mathrm{E}$ and $4 \mathrm{D}$ respectively, are also agglomerate fillers, but in aluminum hydroxide, the fillers are of a larger size than they are in the others. A filler must make intimate contact with the elastomer chains if it is going to contribute to reinforcement of the polymer. Fillers that have a large surface area have more contact area available, and therefore, have a higher potential of reinforcing the elastomer. ${ }^{14}$ Even when using the same chemical composition, a pure version of the material was able to promote better results. The higher the concentration of pure aluminum hydroxide added, the higher was the Shore A hardness, and the greater was the material resistance to traction. Purity seems to have been decisive for the material to perform better.

Halloysite nanotubes are formed from aluminosilicate minerals and have a hollow nanotube structure and a larger luminal diameter that is capable of accommodating different polymer molecules, which offers a larger variety of polymeric composites. Halloysite nanotubes are made up of siloxane and hydroxyl groups, which provide the potential for hydrogen bond formation, thereby improving dispersion. Their surface modification also enhances their wettability and bond formation with different polymers. ${ }^{18}$ In Figure 1, it is possible to compare the tensile strength tests of the diatomaceous earth, calcined alumina, cristobalite, and quartz groups. The diatomaceous earth is composed of $80-90 \%$ silica; calcined alumina is composed of $\mathrm{Al}_{2} \mathrm{O}_{3}$; cristobalite presents a structure alternately pointing up and down; and the quartz has helical arrangements of $\mathrm{SiO} 4$ tetrahedra. Although they are similar, even those with the same chemical composition have different properties, because they have a different crystal structure. This difference did not create differences in the tests evaluated, however, these groups with additions of $20 \%$ and $40 \%$ were statistically similar in both the hardness and tensile strength tests.

The fiberglass filler is a synthetic material primarily made of silica, which does not have a melting point and has long been used for its hardness properties. Generally, fiberglass was added to the matrix of materials with different compositions, which are not vinyl polysiloxane, and was expected to increase the material strength. In Figure 4F, it is possible to observe the dispersed sticks showing a small surface area. In all the tests performed with groups to which glass fiber was added, the performance of the material was the worst. It is possible that the amount of fiber added was not sufficient to promote additional strengthening for this type of silicone formulation.

The only filler that was not a mineral and had a spherical shape was the acrylic polymer, mainly composed of methyl methacrylate, shown in Figure $4 \mathrm{H}$. This organic filler generally offers less affinity and less surface activity in comparison with elastomers. ${ }^{14}$ It does not have the ability to bond to the rubber matrix, because the strongest bond it creates is via Van Der Waals force, which is a relatively weak force. The reduction in area of contact with the organic matrix is directly related to the results of the tensile strength test, because when all the spaces of the organic matrix are not filled, there is a freer polymeric matrix, providing the material with less strength and making it an inactive filler. Furthermore, the acrylic polymer has a very large filler size of 50 microns, and theoretically, the larger the size of filler added to promote the material strength, the lower the tensile strength.

As previously mentioned, fillers may be of the reinforcing or active type, increase the viscosity and hardness of the rubber compound and improve the properties of tensile strength and abrasion resistance up to a limit, as the amount of the load increases. Typically, while the hardness values increase, the values of other properties, such as resilience, decrease.

The fillers aggregation tendency increases as the filler size decreases, and extensive aggregation leads to a polymer with insufficient homogeneity, lower stiffness, and lower compressive strength. These filler aggregate tends to act as a break for occasional initiators when affected by some impact.

The filler size is not only related to viscosity but also to tensile strength and detail reproduction. Shao-Yun et al. ${ }^{12}$ stated that fillers have sizes ranging from $10 \mathrm{~nm}$ to $80 \mathrm{~nm}$ to 1.3 micrometers to 58 micrometers, and for a given filler volume, the tensile strength increases as the filler size decreases. ${ }^{12}$ 
This indicates that the resistance increases with the increase in filler surface area, favoring copy ability in the same way as smaller filler sizes are better able to copy small spaces.

The accuracy of impression materials such as VPS is demonstrably better than other types of impression taking materials. ${ }^{19}$ One of the factors that enhances the accuracy of impressions is the copy ability, which is related to the filler size and viscosity of these materials. This is partly determined by the amount of filler, demonstrating that materials with high viscosity have a larger amount of filler material than those with low viscosity. Materials with a smaller amount of filler have lower viscosity and consequently a greater likelihood of impression distortion. This is probably due to the larger organic matrix, which does not have the ability to impart shape to materials, only to promote the agglutination of the filler. ${ }^{10,17}$

However, when a larger amount of filler was added to the organic matrix in this study, the opposite was observed only with aerosil OX-50 and pure aluminum hydroxide fillers at concentrations of $40 \%$, which showed increase in viscosity and worse copy ability. When comparing concentrations of $20 \%$, the increase in the concentration of the fillers decreased the quality of detail reproduction, because the material was unable to drain from the mold grooves so that it could copy the really necessary details. Whereas the other materials, because they have hybrid filler sizes (10 to $80 \mathrm{~nm}$ ), showed good copy ability, whether in concentrations of $20 \%$ or $40 \%$, probably because the fillers could not enter into full contact with the organic matrix, thereby enhancing the flow of the matrix between the fillers.

However, is not sufficient to have good copy ability only. When an impression is removed from the oral cavity, the material needs to withstand the force that separates it from the teeth and surrounding tissues. If a small strain is applied to a solid material, deformation begins, and the material will continue to deform until the molecular strain establishes a balance with external strains. Most solids exhibit some degree of elastic response, meaning complete deformation recovery after deforming strains. ${ }^{20}$ Thus, elastic recovery becomes important in determining the precision of an impression material. ${ }^{21}$ In this study, the ISO 4823 standard specification was used, which requires recovery of over $96.5 \%$, yielding values between $98.91 \%$ and $99.91 \%$ for pure aluminum hydroxide and quartz, respectively, as shown in Table 2 . These values can be explained by the interstitial filling of organic matrix. In contrast, when complete or almost total filling of the matrix is used, the displacement of the particulates becomes more difficult, and depending on the filler format, slippage occurs. Whereas, the resultant elastic recovery values are due to the impossibility of filler movement. In the case of VPS, this is very small, which explains the strain values of less than $2 \%$.

The tensile strength of a material is defined as the maximum stress the material can withstand under uniaxial traction. ${ }^{12}$ As can be seen in Figure 1, the tensile strength values were derived from the maximum stress that could be applied to the specimens through elongation before they ruptured. This property can be used to indicate the ability of an impression material to withstand interproximal tearing in thin areas. Indeed, clinically it has been observed when taking impressions of a gingival sulcus; where the flap should be copied, it often leads to having no continuity because it is necessary to use the minimum amount of impression material ${ }^{22}$ to achieve the required uniform thickness. Materials with less filler have lower tensile strength when compared with each other, as can be seen Figure 1 when comparing the $20 \%$ fillers with the $40 \%$ fillers, which show an increased resistance in terms of values. Thus, more viscous materials have higher tensile strength values due to the increased amount of filler and tend not to tear so easily. Less viscous materials, on the other hand, produce a smaller film thickness and tear more easily. ${ }^{17,21,22}$

As regards Shore A hardness, we observed a large discrepancy between the values according to filler type. The VPS with 20\% fiberglass revealed mean hardness values of 14.50, which differed statistically from all other fillers except for cristobalite $20 \%$. Its morphology can be observed in Figure 2, in which the filler sizes are similar, and this is explained by the ease of dispersion of the organic matrix around the fillers. The similarity between $40 \%$ aerosil OX-50 and $40 \%$ pure aluminum hydroxide fillers can be 
explained by the nanometer size of the fillers, which promotes increased contact between the organic and inorganic matrix. This, in turn, reduces the interstices of the matrix and increases the hardness values of the material, shown by means of the tip of the tester that cannot penetrate into the VPS. However, the fact that the material is harder does not mean it will be more difficult to handle or remove from the oral cavity. ${ }^{23,24}$

Therefore, the null hypothesis of this study was rejected because there was no statistically significant difference between the mechanical tests, except for the elastic recovery test.

\section{Conclusion}

This study, teaches us about the properties and uses of vinyl polysiloxanes. The incorporation of different filler concentrations considerably modified the properties of most materials. The composition, shape

\section{References}

1. Al-Zarea BK, Sughaireen MG. Comparative analysis of dimensional precision of different silicone impression materials. J Contemp Dent Pract. 2011;12(3):208-15. doi:10.5005/jp-journals-10024-1036

2. Greco GD, Góes IMG, Ferreira JC, Greco ADL. Analysis of dimensional changes of plaster models obtained with the addition silicones in multiple leaks. Arq Bras Odontol. 2009;5(2):53-7. Portuguese.

3. Kumar S, Gandhi UV, Banerjee S. An in vitro study of the bond strength of five adhesives used for vinyl polysiloxane impression materials and tray materials. J Indian Prosthodont Soc. 2014;14(1):61-6. doi:10.1007/s13191-012-0243-5

4. Stober T, Johnson GH, Schmitter M. Accuracy of the newly formulated vinyl siloxanether elastomeric impression material. J Prosthet Dent. 2010;103(4):228-39. doi:10.1016/S0022-3913(10)60035-2

5. Naeimi AH, Moharamzadeh K, Wood DJ, Van Noort R. Relationship between color and translucency of multishaded dental composite resins. Int J Dent. 2012;2012:708032. doi:10.1155/2012/708032

6. Kelly JR, Benetti P. Ceramic materials in dentistry: historical evolution and current practice. Aust Dent J. 2011;56(Suppl 1):s84-96. doi:10.1111/j.1834-7819.2010.01299.x

7. Fortin D, Vargas MA. The spectrum of composites: new techniques and materials. J Am Dent Assoc. 2000;131(Suppl 131):26S-30S. doi:10.14219/jada.archive.2000.0399 and particle size influences the material properties. The correct selection and use of different particles in the same formulation can significantly improve the properties of materials. The type of fillers used in the composition have the potential to influence the clinical performance of an impression material. The use of different fillers may be an important factor for promoting synergy between materials.

\section{Acknowledgements}

F.A.O. is grateful for the support from Financiadora de Estudos e Projeto - FINEP/Brazil (grant 01.10.0709.00). The authors are grateful to Centro de Microscopia Eletrônica do Sul - CEME-SUL - Fundação Universidade Federal do Rio Grande do Sul - FURG/ Brazil for SEM analysis. The authors thank Yller for donating of experimental polyvinylsiloxane, without fillers used in the study.

8. Sakaguchi RL, Power JM. Craig's restorative dental materials. 13th ed. Philadelphia: Elsevier; 2012.

9. ramer NB, Stansbury JW, Bowman CN. Recent advances and developments in composite dental restorative materials. J Dent Res. 2011;90(4):402-16. doi:10.1177/0022034510381263

10. Mandikos MN. Polyvinyl siloxane impression materials: an update on clinical use. Aust Dent J. 1998;43(6):428-34. doi:10.1111/j.1834-7819.1998.tb00204.x

11. Suzuki N, Kiba S, Kamachi Y, Miyamoto N, Yamauchi Y. Unusual reinforcement of silicone rubber compounds containing mesoporous silica particles as inorganic fillers. Phys Chem Chem Phys. 2012;14:3400-7. doi:10.1039/c2cp23864k

12. Shao-Yun F, Xi-Qiao F, Lauke B, Yiu-Wing M. Effects of particle size, particle/matrix interface adhesion and particle loading on mechanical properties of particulate-polymer composites. Compos Part B Eng. 2008;39(6):933-61. doi:10.1016/j.compositesb.2008.01.002

13. Rattanasom N, Saowapark T, Deeprasertkul C. Reinforcement of natural rubber with silica/carbon black hybrid filler. Polym Test. 2007; 26(3):369-77. doi:10.1016/j.polymertesting.2006.12.003

14. Kingender RC, editor. Handbook of specialty elastomers. 1st ed: CRC Press; 2008.

15. Tjan AH, Li T. Effects of reheating on the accuracy of addition silicone putty-wash impressions. J Prosthet Dent. 1991;65(6):743-8. doi:10.1016/S0022-3913(05)80005-8

16. Craig RG, Sun Z. Trends in elastomeric impression materials. Oper Dent. 1994;19(4):138-45. 
17. Carlo HL, Fonseca RB, Soares CJ, Correr AB, Correr-Sobrinho L, Sinhoreti MA. Inorganic particle analysis of dental impression elastomers. Braz Dent J. 2010;21(6):520-7. doi:10.1590/S0103-64402010000600007

18. Rawtani D, Agrawal YK. Multifarious Applications of halloysite nanotubes: a review. Rev Adv Mater Sci. 2012;30(3):282-95.

19. Chen SY, Liang WM, Chen FN. Factors affecting the accuracy of elastometric impression materials. J Dent. 2004;32(8):603-9. doi:10.1016/j.jdent.2004.04.002

20. GuerraBB,FurtadoCRGC, CoutinhoFMB. Rheological evaluation of elastomers and their compounds. Polimeros. 2004;14(4):289-94. Portuguese. doi:10.1590/S0104-14282004000400017

21. Lu H, Nguyen B, Powers JM. Mechanical properties of 3 hydrophilic addition silicone and polyether elastomeric impression materials. J Prosthet Dent. 2004;92(2):151-4. doi:10.1016/j.prosdent.2004.05.016

22. Yi MH, Shim JS, Lee KW, Chung MK. Drying time of tray adhesive for adequate tensile bond strength between polyvinylsiloxane impression and tray resin material. J Adv Prosthodont. 2009;1(12):63-7. doi:10.4047/jap.2009.1.2.63

23. Lawson NC, Burgess JO, Litaker M. Tear strength of five elastomeric impression materials at two setting times and two tearing rates. J Esthet Restor Dent. 2008;20(3):186-93. doi:10.1111/j.1708-8240.2008.00176.x

24. Walker MP, Alderman N, Petrie CS, Melander J, McGuire J. Correlation of impression removal force with elastomeric impression material rigidity and hardness. J Prosthodont. 2013;22(5):362-6. doi:10.1111/jopr.12011 